\title{
An ELECTRE Approach for Multicriteria Interval-Valued Intuitionistic Trapezoidal Fuzzy Group Decision Making Problems
}

\author{
Sireesha Veeramachaneni and Himabindu Kandikonda \\ Department of Applied Mathematics, GITAM Institute of Science, GITAM University, Visakhapatnam 530045, India \\ Correspondence should be addressed to Sireesha Veeramachaneni; vsirisha80@gmail.com
}

Received 24 November 2015; Revised 2 February 2016; Accepted 18 February 2016

Academic Editor: Ibrahim Ozkan

Copyright (C) 2016 S. Veeramachaneni and H. Kandikonda. This is an open access article distributed under the Creative Commons Attribution License, which permits unrestricted use, distribution, and reproduction in any medium, provided the original work is properly cited.

\begin{abstract}
The Multiple Criteria Decision Making (MCDM) is acknowledged as the most useful branch of decision making. It provides an effective framework for comparison based on the evaluation of multiple conflicting criteria. In this paper, a method is proposed to work out multiple attribute group decision making (MAGDM) problems with interval-valued intuitionistic trapezoidal fuzzy numbers (IVITFNs) using Elimination and Choice Translation Reality (ELECTRE) method. A new ranking function based on value and ambiguity is introduced to compare the IVITFNs, which overcomes the limitations of existing methods. An illustrative numerical example is solved to verify the efficiency of the proposed method to select the better alternative.
\end{abstract}

\section{Introduction}

The fuzzy sets (FSs) introduced by Zadeh [1], which are characterized by a membership function, have acquired successful applications in various fields. In fuzzy sets, the membership of an element is defined to be a number from the interval $[0,1]$ and the nonmembership is simply its complement. But, in reality, this hypothesis does not match with human intuition. Thus, in 1986, Atanassov [2] extended the concept of fuzzy sets to intuitionistic fuzzy set (IFS) by characterizing a membership function and a nonmembership function such that the sum of both values is less than or equal to one. However, it is often difficult for experts to exactly quantify their opinions as exact numbers in the interval $[0,1]$ and hence it is more suitable to represent them in interval form [3]. Atanassov and Gargov [4] further generalized the concept of IFS and introduced interval-valued intuitionistic fuzzy sets (IVIFSs) by combining IFS concept with intervalvalued fuzzy set concept. IFSs and IVIFSs have been applied to many different fields such as decision making, supplier selection, and investment options [5]. But the domain in IFSs and IVIFSs is a discrete set; therefore their membership degrees and the nonmembership degrees can only express fuzzy concept in terms of "excellent" or "good." To overcome this limitation, Shu et al. [6] defined intuitionistic triangular fuzzy numbers (ITFNs) such that the domain is a consecutive set. Later on, Wang [7] extended intuitionistic triangular fuzzy number to intuitionistic trapezoidal fuzzy number. Wan [8] introduced the concepts of interval-valued intuitionistic trapezoidal fuzzy numbers (IVITFNs), where the membership and nonmembership values are intervals rather than exact numbers. Hence, there is a need to study the MAGDM using the notion of IVITFNs.

MCDM is well known branch of decision making which deals with decision problems under the presence of a number of decision criteria. In many cases the decision maker information is vague or fuzzy in nature. The classical MCDM methods cannot effectively handle the problems under such imprecision. Bellman and Zadeh [9] introduced the concept of decision making in fuzzy environment. Many researchers combined the fuzzy theory with classical MCDM techniques and proposed fuzzy MCDM methods to solve the problems with imprecision [10-21]. The concept of intuitionistic fuzzy environment was given by Angelov [22]. Li and Wan [23] 
developed new fuzzy linear programming techniques for solving multiple attribute decision making (MADM) problems with multiple types of attribute values and incomplete weight information. Wu and Liu [24] proposed an approach for MAGDM problems with IVITFNs by taking into account the expert's risk attitude. Zhang and Wei [25] developed the E-VIKOR method and TOPSIS method to solve the MCDM problems with hesitant fuzzy set information.

Many MCDM models use "outranking relations" to rank a set of alternatives. The important feature of outranking approach is its noncompensatory nature. The most popular outranking approach amongst the family of outranking approaches is ELECTRE. The ELECTRE approach was first introduced by Benayoun et al. in 1966 [26]. Soon after the introduction of the first version of ELECTRE I [27], this approach was evolved into a number of other variants such as ELECTRE II, III, IV, IS, and TRI [28]. Sevkli [29] proposed fuzzy ELECTRE for supplier selection problem to deal with imprecise and vague nature of linguistic assessment. Vahdani et al. [30] extended ELECTRE with interval weights and data to deal with uncertainty. Later in 2011, Vahdani and Hadipour extended the ELECTRE method based on intervalvalued fuzzy sets [3]. Wei et al. [31] investigated the MAGDM problems in which attribute values take the form of IVITFNs and both the attribute weights and the expert weights take the form of real numbers. Since fuzzy numbers and intuitionistic fuzzy numbers are special cases of IVITFNs, it is significant to develop the most accepted outranking method, "ELECTRE," by taking both attribute values and weights of criteria of MCDM problem in the form of IVITFNs. To do this, we proposed a ranking method for IVITFNs which takes the expert's risk attitude into consideration.

The paper is organized as follows. In Section 2, basic definitions and arithmetic operations of IVITFNs are reviewed. In Section 3, a new ranking of IVITFNs based on value and ambiguity functions is proposed to compare IVITFNs and its advantages over existing methods are presented. In Section 4, the proposed algorithm of ELECTRE method based on IVITFNs is presented. Section 5 provides illustrative examples. Conclusions and future work are presented in Section 6.

\section{Preliminaries}

In this section, we briefly introduce some basic concepts related to interval-valued intuitionistic trapezoidal fuzzy numbers from Xu and Chen [20] and De and Das [32].

Definition 1 (intuitionistic fuzzy set). An intuitionistic fuzzy set over universe of discourse $X$ is of the form

$$
A=\left\{\left\langle x, \mu_{A}(x), v_{A}(x)\right\rangle, x \in X\right\},
$$

where $\mu_{A}$ denotes membership function and $v_{A}$ denotes nonmembership function, with the condition $0 \leq \mu_{A}(x)+$ $v_{A}(x) \leq 1, \mu_{A}(x), v_{A}(x) \in[0,1]$, for all $x \in X$.
Definition 2 (interval-valued intuitionistic fuzzy set). An interval-valued intuitionistic fuzzy set in $A$ over $X$ is an object having the form

$$
\begin{aligned}
& A \\
& =\left\{\left\langle x,\left[\mu_{A}^{L}(x), \mu_{A}^{U}(x)\right],\left[v_{A}^{L}(x), v_{A}^{U}(x)\right]\right\rangle, x \in X\right\},
\end{aligned}
$$

where

$$
\mu_{A}^{L}, \mu_{A}^{U}, v_{A}^{L}, v_{A}^{U}: X \longrightarrow[0,1], \quad \mu_{A}^{L} \leq \mu_{A}^{U}, v_{A}^{L} \leq v_{A}^{U} .
$$

Definition 3 (IVIFNs score function). Let $\widetilde{A}=$ $\left(\left[\mu_{\widetilde{A}}^{L}, \mu_{\widetilde{A}}^{U}\right],\left[v_{\widetilde{A}}^{L}, v_{\widetilde{A}}^{U}\right]\right)$ be an interval-valued intuitionistic fuzzy number. The score function of $\widetilde{A}, S_{X}(\widetilde{A})$, is represented as

$$
S_{X}(\widetilde{A})=\frac{\mu_{\widetilde{A}}^{L}+\mu_{\widetilde{A}}^{U}-v_{\widetilde{A}}^{L}-v_{\widetilde{A}}^{U}}{2}, \quad S_{X}(\widetilde{A}) \in[-1,1] .
$$

Definition 4 (IVIFNs accuracy function). Let $\widetilde{A}=$ $\left(\left[\mu_{\widetilde{A}}^{L}, \mu_{\widetilde{A}}^{U}\right],\left[v_{\widetilde{A}}^{L}, v_{\widetilde{A}}^{U}\right]\right)$ be an interval-valued intuitionistic fuzzy number. The accuracy function of $\widetilde{A}, H_{X}(\widetilde{A})$, is represented as

$$
H_{X}(\widetilde{A})=\frac{\mu_{\widetilde{A}}^{L}+\mu_{\widetilde{A}}^{U}+v_{\widetilde{A}}^{L}+v_{\widetilde{A}}^{U}}{2}, \quad H_{X}(\widetilde{A}) \in[0,1] .
$$

Definition 5 (IVITFS). Let $\widetilde{A}$ be an interval-valued intuitionistic trapezoidal fuzzy set (IVITFS); its interval-valued membership function is

$$
\begin{aligned}
& \mu_{\widetilde{A}}^{U}(x)= \begin{cases}\frac{x-a}{b-a} \mu_{\widetilde{A}}^{U}, & a \leq x<b ; \\
\mu_{\widetilde{A}}^{U}, & b \leq x \leq c ; \\
\frac{d-x}{d-c} \mu_{\widetilde{A}}^{U}, & c<x \leq d ; \\
0, & \text { others, }\end{cases} \\
& \mu_{\widetilde{A}}^{L}(x)= \begin{cases}\frac{x-a}{b-a} \mu_{\widetilde{A}}^{L}, & a \leq x<b ; \\
\mu_{\widetilde{A}}^{L}, & b \leq x \leq c ; \\
\frac{d-x}{d-c} \mu_{\widetilde{A}}^{L}, & c<x \leq d ; \\
0, & \text { others. }\end{cases}
\end{aligned}
$$


Its interval-valued nonmembership function is

$$
\begin{aligned}
& v_{\widetilde{A}}^{U}(x)= \begin{cases}\frac{b-x+v_{\widetilde{A}}^{U}(x-a)}{b-a}, & a \leq x<b ; \\
\frac{v_{\widetilde{A}}^{U},}{x-c+v_{\widetilde{A}}^{U}(d-x)} & b \leq x \leq c ; \\
0, & c<x \leq d ;\end{cases} \\
& v_{\widetilde{A}}^{L}(x)= \begin{cases}\frac{b-x+v_{\widetilde{A}}^{L}(x-a)}{b-a}, & \text { others, } \\
v_{\widetilde{A}}^{\frac{L}{2}}, & b \leq x \leq c ; \\
\frac{x-c+v_{\widetilde{A}}^{L}(d-x)}{d-c}, & c<x \leq d ; \\
0, & \text { others, }\end{cases}
\end{aligned}
$$

where $0 \leq \mu_{\widetilde{A}}^{L} \leq \mu_{\widetilde{A}}^{U} \leq 1 ; 0 \leq v_{\widetilde{A}}^{L} \leq v_{\widetilde{A}}^{U} \leq 1 ; 0 \leq$ $\mu_{\widetilde{A}}^{U}+v_{\widetilde{A}}^{U} \leq 1 ; 0 \leq \mu_{\widetilde{A}}^{L}+v_{\widetilde{A}}^{L} \leq 1 ; a, b, c, d \in R$. Then $\tilde{a}=\left([a, b, c, d] ;\left[\mu_{\tilde{a}}^{L}, \mu_{\widetilde{a}}^{U}\right] ;\left[v_{\widetilde{a}}^{L}, v_{\widetilde{a}}^{U}\right]\right)$ is called interval-valued intuitionistic trapezoidal fuzzy set (IVITFS).

Definition 6 (arithmetic operation law of IVITFS). Let $\widetilde{A}_{1}=\left(\left[a_{1}, b_{1}, c_{1}, d_{1}\right] ;\left[\mu_{\widetilde{A}_{1}}^{L}, \mu_{\widetilde{A}_{1}}^{U}\right] ;\left[v_{\widetilde{A}_{1}}^{L}, v_{\widetilde{A}_{1}}^{U}\right]\right)$ and $\widetilde{A}_{2}=$ $\left(\left[a_{2}, b_{2}, c_{2}, d_{2}\right] ;\left[\mu_{\widetilde{A}_{2}}^{L}, \mu_{\widetilde{A}_{2}}^{U}\right] ;\left[v_{\widetilde{A}_{2}}^{L}, v_{\widetilde{A}_{2}}^{U}\right]\right)$ be two interval-valued intuitionistic trapezoidal fuzzy numbers; then

$$
\begin{aligned}
& \widetilde{A}_{1} \oplus \widetilde{A}_{2}=\left(\left[a_{1}+a_{2}, b_{1}+b_{2}, c_{1}+c_{2}, d_{1}+d_{2}\right] ;\right. \\
& \min \left\{\left[\mu_{\widetilde{A}_{1}}^{L}, \mu_{\widetilde{A}_{1}}^{U}\right] ;\left[v_{\widetilde{A}_{1}}^{L}, v_{\widetilde{A}_{1}}^{U}\right]\right\} ; \\
& \left.\quad \max \left\{\left[\mu_{\widetilde{A}_{2}}^{L}, \mu_{\widetilde{A}_{2}}^{U}\right] ;\left[v_{\widetilde{A}_{2}}^{L}, v_{\widetilde{A}_{2}}^{U}\right]\right\}\right), \\
& \widetilde{A}_{1}-\widetilde{A}_{2}=\left(\left[a_{1}-a_{2}, b_{1}-b_{2}, c_{1}-c_{2}, d_{1}-d_{2}\right] ;\right. \\
& \quad \min \left\{\left[\mu_{\widetilde{A}_{1}}^{L}, \mu_{\widetilde{A}_{1}}^{U}\right] ;\left[v_{\widetilde{A}_{1}}^{L}, v_{\widetilde{A}_{1}}^{U}\right]\right\} ; \\
& \left.\max \left\{\left[\mu_{\widetilde{A}_{2}}^{L}, \mu_{\widetilde{A}_{2}}^{U}\right] ;\left[v_{\widetilde{A}_{2}}^{L}, v_{\widetilde{A}_{2}}^{U}\right]\right\}\right)
\end{aligned}
$$

for $\widetilde{A}_{1}>0, \widetilde{A}_{2}>0$; consider

$$
\begin{aligned}
& \widetilde{A}_{1} \otimes \widetilde{A}_{2}=\left(\left[a_{1} \cdot a_{2}, b_{1} \cdot b_{2}, c_{1} \cdot c_{2}, d_{1} \cdot d_{2}\right] ;\right. \\
& \min \left\{\left[\mu_{\widetilde{A}_{1}}^{L}, \mu_{\widetilde{A}_{1}}^{U}\right] ;\left[v_{\widetilde{A}_{1}}^{L}, v_{\widetilde{A}_{1}}^{U}\right]\right\} ; \\
&\left.\max \left\{\left[\mu_{\widetilde{A}_{2}}^{L}, \mu_{\widetilde{A}_{2}}^{U}\right] ;\left[v_{\widetilde{A}_{2}}^{L}, v_{\widetilde{A}_{2}}^{U}\right]\right\}\right), \\
& \frac{\widetilde{A}_{1}}{\widetilde{A}_{2}}=\left(\left[\frac{a_{1}}{d_{2}}, \frac{b_{1}}{c_{2}}, \frac{c_{1}}{b_{2}}, \frac{d_{1}}{a_{2}}\right] ;\right. \\
& \quad \min \left\{\left[\mu_{\widetilde{A}_{1}}^{L}, \mu_{\widetilde{A}_{1}}^{U}\right] ;\left[v_{\widetilde{A}_{1}}^{L}, v_{\widetilde{A}_{1}}^{U}\right]\right\} ; \\
&\left.\quad \max \left\{\left[\mu_{\widetilde{A}_{2}}^{L}, \mu_{\widetilde{A}_{2}}^{U}\right] ;\left[v_{\widetilde{A}_{2}}^{L}, v_{\widetilde{A}_{2}}^{U}\right]\right\}\right) .
\end{aligned}
$$

Definition 7 ( $\alpha$-cut set of IVITFN). $\alpha$-cut set of an IVITFN, $\widetilde{A}=\left([a, b, c, d] ;\left[\mu_{\widetilde{A}}^{L}, \mu_{\widetilde{A}}^{U}\right] ;\left[v_{\widetilde{A}}^{L}, v_{\widetilde{A}}^{U}\right]\right)$, is a crisp subset of $R$, which is defined as $\widetilde{A}_{\alpha}=\left\{x / \mu_{\widetilde{A}}(x) \geq \alpha\right\}$, where $0 \leq \alpha \leq \mu_{\widetilde{A}}$ is a closed interval denoted by

$$
\begin{aligned}
\widetilde{A}_{\alpha} & =\left[L_{\widetilde{A}}(\alpha), R_{\widetilde{A}}(\alpha)\right] \\
& =\left[a+\frac{\alpha}{S_{x}(\widetilde{A})}(b-a), d+\frac{\alpha}{S_{x}(\widetilde{A})}(c-d)\right],
\end{aligned}
$$

where $S_{x}(\widetilde{A})=\left(\mu_{\widetilde{A}}^{L}+\mu_{\widetilde{A}}^{U}-v_{\widetilde{A}}^{L}-v_{\widetilde{A}}^{U}\right) / 2$ is the score function of $\widetilde{A}$.

Definition 8 ( $\beta$-cut set of IVITFN). $\beta$-cut set of an IVITFN, $\widetilde{A}=\left([a, b, c, d] ;\left[\mu_{\widetilde{A}}^{L}, \mu_{\widetilde{A}}^{U}\right] ;\left[v_{\widetilde{A}}^{L}, v_{\widetilde{A}}^{U}\right]\right)$, is a crisp subset of $R$, which is defined as $\widetilde{A}_{\beta}=\left\{x / v_{\widetilde{A}}(x) \leq \beta\right\}$, where $v_{\widetilde{A}} \leq \beta \leq 1$ is a closed interval denoted by

$$
\begin{aligned}
\widetilde{A}_{\beta} & =\left[L_{\widetilde{A}}(\beta), R_{\widetilde{A}}(\beta)\right] \\
& =\left[\frac{(1-\beta) b+\left(\beta-H_{x}(\widetilde{A})\right) a}{1-H_{x}(\widetilde{A})},\right. \\
& \left.\frac{(1-\beta) c+\left(\beta-H_{x}(\widetilde{A})\right) d}{1-H_{x}(\widetilde{A})}\right],
\end{aligned}
$$

where $H_{x}(\widetilde{A})=\left(\mu_{\widetilde{A}}^{L}+\mu_{\widetilde{A}}^{U}+v_{\widetilde{A}}^{L}+v_{\widetilde{A}}^{U}\right) / 2$ is the accuracy function of $\widetilde{A}$.

2.1. Existing Wu and Liu Ranking of IVITFN. For an intervalvalued intuitionistic trapezoidal fuzzy number $\widetilde{A}$, Wu and Liu [24] ranked the IVITFN using score and expected function. The score expected function, $I\left(S_{x}(\widetilde{A})\right)$, and accurate expected function of $\widetilde{A}$ are given by

$$
\begin{gathered}
I\left(S_{x}(\widetilde{A})\right)=\frac{S_{x}(\widetilde{A})}{2}[(1-\partial)(a+b)+\partial(c+d)], \\
I\left(H_{x}(\widetilde{A})\right)=\frac{H_{x}(\widetilde{A})}{2}[(1-\partial)(a+b)+\partial(c+d)],
\end{gathered}
$$

where $S_{x}(\widetilde{A})$ and $H_{x}(\widetilde{A})$ are the score and accuracy function of $\widetilde{A}$ and $\partial \in[0,1]$ indicates the risk tolerance of the expert.

Ranking is defined as follows:

(1) The larger the value of $I\left(S_{x}(\widetilde{A})\right)$, the more the degree of score of $\widetilde{A}$.

(2) If score expected functions of two IVITFNs are the same then find the accurate expected functions; the larger the value of $I\left(H_{x}(\widetilde{A})\right)$, the more the degree of accuracy of $\widetilde{A}$.

(3) If the values of score and accurate expected function are the same then the IVITFNs are said to be equal. 


\section{Proposed Ranking of IVITFNs Based on Value and Ambiguity}

In this section we propose a method to rank IVITFN based on value and ambiguity defined by Delgado et al. [33], using alpha-cuts and beta-cuts. The parameter "value" allows us to represent an IVITFN as a real value. It assesses the ill-defined magnitude represented by the fuzzy number. "Ambiguity" measures how much vagueness is present in the ill-defined magnitude of the fuzzy number. Hence the relation is similar to mean and variance in statistics.

Definition 9 (value of IVITFN). The values of membership function $\mu_{\widetilde{A}}(x)$ and nonmembership function $v_{\widetilde{A}}(x)$ for the IVITFN $\widetilde{A}$ are, respectively, defined as

$$
\begin{aligned}
& V_{\mu}(\widetilde{A})=\int_{0}^{S_{x}(\widetilde{A})} \frac{L_{\widetilde{A}}(\alpha)+R_{\widetilde{A}}(\alpha)}{2} f(\alpha) d \alpha, \\
& V_{v}(\widetilde{A})=\int_{H_{X}(\widetilde{A})}^{1} \frac{L_{\widetilde{A}}(\beta)+R_{\widetilde{A}}(\beta)}{2} g(\beta) d \beta,
\end{aligned}
$$

where the function $f(\alpha)$ is a nonnegative and nondecreasing function on the interval $\left[0, S_{x}(\widetilde{A})\right]$ with $f(0)=0$ and $\int_{0}^{S_{x}(\widetilde{A})} f(\alpha) d \alpha=S_{x}(\widetilde{A})$; the function $g(\beta)$ is a nonnegative and nonincreasing function on the interval $\left[H_{x}(\widetilde{A}), 1\right]$ with $g(\beta)=1$ and $\int_{H_{X}(\widetilde{A})}^{1} g(\beta) d \beta=1-H_{x}(\widetilde{A})$.

For $f(\alpha)=2 \alpha / S_{x}(\widetilde{A}), g(\beta)=2(1-\beta) /\left(1-H_{x}(\widetilde{A})\right)$. Consider

$$
\begin{aligned}
& V_{\mu}(\widetilde{A})=\int_{0}^{S_{x}(\widetilde{A})} \frac{1}{2}\left[a+\frac{\alpha(b-a)}{S_{x}(\widetilde{A})}+d+\frac{\alpha(c-d)}{S_{x}(\widetilde{A})}\right] \\
& \frac{2 \alpha}{S_{x}(\widetilde{A})} d \alpha=\frac{1}{S_{x}(\widetilde{A})}\left[\int_{0}^{S_{x}(\widetilde{A})}(a+d) \alpha d \alpha\right] \\
& +\frac{1}{S_{x}^{2}(\widetilde{A})}\left[\int_{0}^{S_{x}(\widetilde{A})}(b+c-a-d) \alpha^{2} d \alpha\right] \\
& =\frac{a+2 b+2 c+d}{6} S_{x}(\widetilde{A}) \text {, } \\
& V_{v}(\widetilde{A})=\int_{H_{x}(\widetilde{A})}^{1} \frac{1}{2}\left[\frac{(1-\beta) b+\left(\beta-H_{x}(\widetilde{A})\right) a}{1-H_{x}(\widetilde{A})}\right. \\
& \left.+\frac{(1-\beta) c+\left(\beta-H_{x}(\widetilde{A}) d\right)}{1-H_{x}(\widetilde{A})}\right] \frac{2(1-\beta)}{1-H_{x}(\widetilde{A})} d \beta \\
& =\frac{1}{\left(1-H_{x}(\widetilde{A})\right)^{2}} \int_{H_{x}(\widetilde{A})}^{1}[(1-\beta)(c+b) \\
& \left.+\beta(a+d)-H_{x}(\widetilde{A})(a+d)\right](1-\beta) d \beta
\end{aligned}
$$

$$
\begin{aligned}
& =\frac{1}{\left(1-H_{x}(\widetilde{A})\right)^{2}} \int_{H_{x}(\widetilde{A})}^{1}[(1-\beta)(c+b) \\
& \left.-(1-\beta)(a+d)+\left(1-H_{x}(\widetilde{A})\right)(a+d)\right](1 \\
& -\beta) d \beta=\frac{1}{\left(1-H_{x}(\widetilde{A})\right)^{2}} \\
& \cdot \int_{H_{x}(\widetilde{A})}^{1}[(1-\beta)(c+b)-(1-\beta)(a+d) \\
& \left.+\left(1-H_{x}(\widetilde{A})\right)(a+d)\right](1-\beta) d \beta \\
& =\frac{1}{\left(1-H_{x}(\widetilde{A})\right)^{2}} \int_{H_{x}(\widetilde{A})}^{1}[(1-\beta)(c+b-a-d) \\
& \left.+\left(1-H_{x}(\widetilde{A})\right)(a+d)\right](1-\beta) d \beta \\
& =\frac{a+2 b+2 c+d}{6}\left(1-H_{x}(\widetilde{A})\right) .
\end{aligned}
$$

Definition 10 (ambiguity of IVITFN). The ambiguities of membership function $\mu_{\widetilde{A}}(x)$ and nonmembership function $v_{\widetilde{A}}(x)$ for the IVITFN $\widetilde{A}$ are, respectively, defined as

$$
\begin{aligned}
& A_{\mu}(\widetilde{A})=\int_{0}^{S_{x}(\widetilde{A})}\left(R_{\widetilde{A}}(\alpha)-L_{\widetilde{A}}(\alpha)\right) f(\alpha) d \alpha, \\
& A_{v}(\widetilde{A})=\int_{H_{X}(\widetilde{A})}^{1}\left(R_{\widetilde{A}}(\beta)-L_{\widetilde{A}}(\beta)\right) g(\beta) d \beta .
\end{aligned}
$$

For $f(\alpha)=2 \alpha / S_{x}(\widetilde{A}), g(\beta)=2(1-\beta) /\left(1-H_{x}(\widetilde{A})\right)$. Consider

$$
\begin{aligned}
A_{\mu}(\widetilde{A}) & =\int_{0}^{S_{x}(\widetilde{A})}\left[\left(d+\frac{\alpha(c-d)}{S_{x}(\widetilde{A})}\right)\right. \\
& \left.-\left(a+\frac{\alpha(b-a)}{S_{x}(\widetilde{A})}\right)\right] \frac{2 \alpha}{S_{x}(\widetilde{A})} d \alpha \\
& =\frac{2}{S_{x}(\widetilde{A})}\left[\int_{0}^{S_{x}(\widetilde{A})}(d-a) \alpha d \alpha\right] \\
+ & \frac{2}{S_{x}{ }^{2}(\widetilde{A})}\left[\int_{0}^{S_{x}(\widetilde{A})}(c-d+a-b) \alpha^{2} d \alpha\right] \\
& =\frac{(d-a)-2(b-c)}{3} S_{x}(\widetilde{A}), \\
A_{v} & (\widetilde{A})=\int_{H_{x}(\widetilde{A})}^{1}\left[\frac{(1-\beta) c+\left(\beta-H_{x}(\widetilde{A}) d\right)}{1-H_{x}(\widetilde{A})}\right. \\
- & \frac{\left.(1-\beta) b+\left(\beta-H_{x}(\widetilde{A})\right) a\right] \frac{2(1-\beta)}{1-H_{x}(\widetilde{A})} d \beta}{1-H_{x}(\widetilde{A})}
\end{aligned}
$$




$$
\begin{aligned}
& =\frac{2}{\left(1-H_{x}(\widetilde{A})\right)^{2}} \int_{H_{x}(\widetilde{A})}^{1}[(1-\beta)(c-b) \\
& \left.+\beta(d-a)-H_{x}(\widetilde{A})(d-a)\right](1-\beta) d \beta \\
& =\frac{2}{\left(1-H_{x}(\widetilde{A})\right)^{2}} \int_{H_{x}(\widetilde{A})}^{1}[(1-\beta)(c-b) \\
& \left.-(1-\beta)(d-a)+\left(1-H_{x}(\widetilde{A})\right)(d-a)\right](1 \\
& -\beta) d \beta=\frac{2}{\left(1-H_{x}(\widetilde{A})\right)^{2}} \\
& \cdot \int_{H_{x}(\widetilde{A})}^{1}[(1-\beta)(c-b+a-d) \\
& \left.+\left(1-H_{x}(\widetilde{A})\right)(d-a)\right](1-\beta) d \beta \\
& =\frac{(d-a)-2(b-c)}{3}\left(1-H_{x}(\widetilde{A})\right) .
\end{aligned}
$$

Definition 11 (value index of IVITFN). Based on the values of membership function and nonmembership function, the value index of IVITFN $\widetilde{A}=\left([a, b, c, d] ;\left[\mu_{\widetilde{A}}^{L}, \mu_{\widetilde{A}}^{U}\right] ;\left[v_{\widetilde{A}}^{L}, v_{\widetilde{A}}^{U}\right]\right)$ is defined as

$$
\begin{aligned}
V & (\widetilde{A})=k V_{\mu}(\widetilde{A})+(1-k) V_{v}(\widetilde{A}) \\
= & k\left[\frac{a+2 b+2 c+d}{6} S_{x}(\widetilde{A})\right]+(1-k) \\
\cdot & {\left[\frac{a+2 b+2 c+d}{6}\left(1-H_{x}(\widetilde{A})\right)\right] } \\
= & {\left[\frac{a+2(b+c)+d}{6}\right] } \\
\cdot & \left(k S_{x}(\widetilde{A})+(1-k)\left(1-H_{x}(\widetilde{A})\right)\right),
\end{aligned}
$$

where $k \in[0,1]$ varies according to the decision maker's risk attitude. The expert is said to be risk-averse if $k<0.5$, riskprone if $k>0.5$, and risk-neutral if $k=0.5$.

For $k=0.5$,

$$
V(\widetilde{A})=\frac{a+2(b+c)+d}{12}\left(1+S_{x}(\widetilde{A})-H_{x}(\widetilde{A})\right) .
$$

If $\left[\mu_{\widetilde{A}}^{L}, \mu_{\widetilde{A}}^{U}\right]=[1,1]$ and $\left[v_{\widetilde{A}}^{L}, v_{\widetilde{A}}^{U}\right]=[0,0]$, then the IVITFN degenerates to a trapezoidal fuzzy number $\widetilde{A}=[a, b, c, d]$. In this case, for $k=0.5$,

$$
V(\widetilde{A})=\frac{a+2 b+2 c+d}{12} .
$$

Definition 12 (ambiguity index of IVITFN). Based on the ambiguities of membership function and nonmembership function, the ambiguity index of IVITFN $\widetilde{A}=$ $\left([a, b, c, d] ;\left[\mu_{\widetilde{A}}^{L}, \mu_{\widetilde{A}}^{U}\right] ;\left[v_{\widetilde{A}}^{L}, v_{\widetilde{A}}^{U}\right]\right)$ is defined as

$$
\begin{aligned}
A(\widetilde{A}) & =k A_{\mu}(\widetilde{A})+(1-k) A_{v}(\widetilde{A}) \\
& =k\left[\frac{(d-a)-2(b-c)}{3} S_{x}(\widetilde{A})\right]+(1-k) \\
& \cdot\left[\frac{(d-a)-2(b-c)}{3}\left(1-H_{x}(\widetilde{A})\right)\right] \\
& =\left[\frac{(d-a)-2(b-c)}{3}\right] \\
& \cdot\left(k S_{x}(\widetilde{A})+(1-k)\left(1-H_{x}(\widetilde{A})\right)\right),
\end{aligned}
$$

where $k \in[0,1]$ varies according to the decision maker's risk attitude.

For $k=0.5$,

$$
A(\widetilde{A})=\frac{(d-a)-2(b-c)}{6}\left(1+S_{x}(\widetilde{A})-H_{x}(\widetilde{A})\right) .
$$

Based on the value index function $V(\widetilde{A})$ and the ambiguity index function $A(\widetilde{A})$, the following ranking procedure is proposed.

For two interval-valued intuitionistic trapezoidal fuzzy numbers,

$$
\begin{aligned}
& \widetilde{A}_{1}=\left(\left[a_{1}, b_{1}, c_{1}, d_{1}\right] ;\left[\mu_{\widetilde{A}_{1}}^{L}, \mu_{\widetilde{A}_{1}}^{U}\right] ;\left[v_{\widetilde{A}_{1}}^{L}, v_{\widetilde{A}_{1}}^{U}\right]\right), \\
& \widetilde{A}_{2}=\left(\left[a_{2}, b_{2}, c_{2}, d_{2}\right] ;\left[\mu_{\widetilde{A}_{2}}^{L}, \mu_{\widetilde{A}_{2}}^{U}\right] ;\left[v_{\widetilde{A}_{2}}^{L}, v_{\widetilde{A}_{2}}^{U}\right]\right),
\end{aligned}
$$

(1) if $V\left(\widetilde{A}_{1}\right)<V\left(\widetilde{A}_{2}\right)$, then $\widetilde{A}_{1}<\widetilde{A}_{2}$;

(2) if $V\left(\widetilde{A}_{1}\right)>V\left(\widetilde{A}_{2}\right)$, then $\widetilde{A}_{1}>\widetilde{A}_{2}$;

(3) if $V\left(\widetilde{A}_{1}\right)=V\left(\widetilde{A}_{2}\right)$, then find $A\left(\widetilde{A}_{1}\right)$ and $A\left(\widetilde{A}_{2}\right)$;

(i) if $A\left(\widetilde{A}_{1}\right)<A\left(\widetilde{A}_{2}\right)$, then $\widetilde{A}_{1}<\widetilde{A}_{2}$;

(ii) if $A\left(\widetilde{A}_{1}\right)>A\left(\widetilde{A}_{2}\right)$, then $\widetilde{A}_{1}>\widetilde{A}_{2}$;

(iii) if $A\left(\widetilde{A}_{1}\right)=A\left(\widetilde{A}_{2}\right)$, then $\widetilde{A}_{1}=\widetilde{A}_{2}$.

Remark 13. Throughout the paper, we discuss the methodology by assuming that the decision maker is risk-neutral. The same can be discussed in other two cases also.

Advantages of Proposed Ranking. The advantage of the proposed method is shown by comparison with existing methods in the literature.

Example 14. Consider two IVITFNs:

$$
\begin{aligned}
& \widetilde{A}=([0.2,0.3,0.4,0.5] ;[0.4,0.6] ;[0.2,0.3]), \\
& \widetilde{B}=([0.4,0.5,0.6,0.7] ;[0.3,0.5] ;[0.2,0.3]) ;
\end{aligned}
$$


the score and accurate expected values of $\widetilde{A}$ and $\widetilde{B}$ by Wu and Liu [24] are

$$
\begin{aligned}
& I\left(S_{x}(\widetilde{A})\right)=0.0875, \\
& I\left(S_{x}(\widetilde{B})\right)=0.0825
\end{aligned}
$$

and hence $\widetilde{A}>\widetilde{B}$.

And, by proposed ranking, we get

$$
\begin{aligned}
& V(\widetilde{A})=0.04375, \\
& V(\widetilde{B})=0.04125 .
\end{aligned}
$$

and therefore $\widetilde{A}>\widetilde{B}$.

Example 15. Consider

$$
\begin{aligned}
\widetilde{A} & =([0.3,0.4,0.5,0.6] ;[1,1] ;[0,0]), \\
\widetilde{B} & =([0.2,0.3,0.6,0.7] ;[1,1] ;[0,0]), \\
\widetilde{C} & =([0.1,0.4,0.5,0.8] ;[1,1] ;[0,0]) ;
\end{aligned}
$$

the score and accurate expected values of $\widetilde{A}, \widetilde{B}$, and $\widetilde{C}$ by Wu and Liu are

$$
\begin{gathered}
I\left(S_{x}(\widetilde{A})\right)=0.45, \\
I\left(S_{x}(\widetilde{B})\right)=0.45, \\
I\left(S_{x}(\widetilde{C})\right)=0.45, \\
I\left(H_{x}(\widetilde{A})\right)=0.45, \\
I\left(H_{x}(\widetilde{B})\right)=0.45, \\
I\left(H_{x}(\widetilde{C})\right)=0.45
\end{gathered}
$$

$$
\Longrightarrow \widetilde{A}=\widetilde{B}=\widetilde{C}
$$

which is not true by intuition.

But, by using the proposed method, we have

$$
\begin{aligned}
& V(\widetilde{A})=0.225, \\
& V(\widetilde{B})=0.225, \\
& V(\widetilde{C})=0.225, \\
& A(\widetilde{A})=0.0833, \\
& A(\widetilde{B})=0.1833, \\
& A(\widetilde{C})=0.15
\end{aligned}
$$$$
\Longrightarrow \widetilde{B}>\widetilde{C}>\widetilde{A} \text {. }
$$

Example 16. Consider

$$
\begin{aligned}
& \widetilde{A}=([0.5,0.6,0.7,0.75] ;[1,1] ;[0,0]), \\
& \widetilde{B}=([0.45,0.65,0.7,0.75] ;[1,1] ;[0,0])
\end{aligned}
$$

Then

$$
\begin{gathered}
I\left(S_{x}(\widetilde{A})\right)=0.6375 \\
I\left(S_{x}(\widetilde{B})\right)=0.6375 \\
I\left(H_{x}(\widetilde{A})\right)=0.6375 \\
I\left(H_{x}(\widetilde{B})\right)=0.6375
\end{gathered}
$$

$$
\Longrightarrow \widetilde{A}=\widetilde{B} \text {. }
$$

By proposed ranking,

$$
\begin{aligned}
& V(\widetilde{A})=0.3208, \\
& V(\widetilde{B})=0.325,
\end{aligned}
$$

and hence we get $\widetilde{B}>\widetilde{A}$.

From these examples, it is proved that the proposed method can rank IVITFNs effectively when compared to $\mathrm{Wu}$ and Liu.

\section{Proposed Algorithm of ELECTRE Method for IVITFNs}

ELECTRE is the most popular outranking approach amongst the family of outranking approaches. It is used to rank the set of alternatives in many MCDM problems. In the proposed method, criteria values of each alternative and criteria weights are considered as IVITTFNs. This representation gives an opportunity to decision maker to define the membership and nonmembership in the form of an interval as well as discussing the problem on a consecutive set.

Let $A_{1}, A_{2}, A_{3}, \ldots, A_{m}$ be $m$ possible alternatives and let $C_{1}, C_{2}, C_{3}, \ldots, C_{n}$ be $n$ criteria with which alternatives' performance is measured. Let $\widetilde{\alpha}_{i j}$ be the performance of alternative with respect to criterion, which is expressed as IVITFN, represented by

$$
\widetilde{\alpha}_{i j}=\left(\left[a_{i j}, b_{i j}, c_{i j}, d_{i j}\right] ;\left[\mu_{\tilde{\alpha}_{i j}}^{-}, \mu_{\tilde{\alpha}_{i j}}^{+}\right] ;\left[v_{\widetilde{\alpha}_{i j}}^{-}, v_{\widetilde{\alpha}_{i j}}^{+}\right]\right) .
$$

Let $\widetilde{W}=\left[\widetilde{w}_{j}^{k}\right]_{k \times n}$ be the weight matrix, where

$$
\widetilde{w}_{j}^{k}=\left(\left[w_{1 j}^{k}, w_{2 j}^{k}, w_{3 j}^{k}, w_{4 j}^{k}\right] ;\left[\mu_{\widetilde{w}_{j}^{k}}^{L}, \mu_{\widetilde{w}_{j}^{k}}^{U}\right] ;\left[v_{\widetilde{w}_{j}^{k}}^{L}, v_{\widetilde{w}_{j}^{k}}^{U}\right]\right)
$$


is the weight of the criterion $C_{j}$ which is also an IVITFN. Then the average weight of each criterion is calculated using the equation

$$
\widetilde{w}_{j}=\frac{1}{k}\left[\widetilde{w}_{j}^{1} \oplus \widetilde{w}_{j}^{2} \oplus \cdots \oplus \widetilde{w}_{j}^{k}\right]
$$

here $\widetilde{w}_{j}^{k}$ is the assessment of the $k$ th decision maker.

Step 1 (construction of decision matrix). Let $k$ decision makers be involved in the decision making. The rating of the alternate with respect to each criterion can be calculated as

$$
\tilde{a}_{i j}=\frac{1}{k}\left[\tilde{a}_{i j}^{1} \oplus \tilde{a}_{i j}^{2} \oplus \cdots \oplus \tilde{a}_{i j}^{k}\right]
$$

where $\tilde{a}_{i j}^{k}$ is the assessment of the $k$ th decision maker and $\oplus$ is the sum operator applied to the IVITFNs as defined in Definition 6.

Then the decision matrix for a multicriteria decision making problem (MCDMP) is defined as $D=\left[\widetilde{a}_{i j}\right]_{m \times n}$.

Step 2 (calculation of normalized decision matrix). The normalization of the decision matrix $D$ is as follows:

$$
\tilde{p}_{i j}=\frac{\tilde{a}_{i j}}{\sqrt{\sum_{i=1}^{m} \tilde{a}_{i j}^{2}}}
$$

Step 3 (calculation of the weighted normalized decision matrix). By taking into account the weight of each criterion, the weighted normalized decision matrix, denoted by $R$, is constructed as

$$
R=\left[\widetilde{r}_{i j}\right]_{m \times n},
$$

where $\tilde{r}_{i j}=\widetilde{p}_{i j} \otimes \widetilde{w}_{j}$ and $\otimes$ is the multiplication operator applied to the IVITFNs as defined in Definition 6.

Step 4 (estimating the concordance and discordance IVITFNs sets). The set of given IVITFN indicators are divided into two different sets of concordance and discordance IVITFN sets. For each pair of alternatives $A_{k}$ and $A_{l}$, where $k, l=$ $1,2,3, \ldots, m$ and $k \neq l$, the IVITFN concordance set $C_{k, l}$ is the set which contains all the criteria for which the alternative $A_{k}$ is superior to the alternative $A_{l}$, and it is represented by

$$
\begin{aligned}
C_{k, l} & =\left\{\frac{j}{\left(\left[r_{1 k j}, r_{2 k j}, r_{3 k j}, r_{4 k j}\right] ;\left[\mu_{k j}^{L}, \mu_{k j}^{U}\right] ;\left[v_{k j}^{L}, v_{k j}^{U}\right]\right)}\right. \\
& \left.\geq\left(\left[r_{1 l j}, r_{2 l j}, r_{3 l j}, r_{4 l j}\right] ;\left[\mu_{l j}^{L}, \mu_{l j}^{U}\right] ;\left[v_{l j}^{L}, v_{l j}^{U}\right]\right)\right\},
\end{aligned}
$$

and the IVITFN discordance set $D_{k, l}$, the complement of the set $C_{k, l}$, is given by

$$
\begin{aligned}
D_{k, l} & =\left\{\frac{j}{\left(\left[r_{1 k j}, r_{2 k j}, r_{3 k j}, r_{4 k j}\right] ;\left[\mu_{k j}^{L}, \mu_{k j}^{U}\right] ;\left[v_{k j}^{L}, v_{k j}^{U}\right]\right)}\right. \\
& \left.<\left(\left[r_{1 l j}, r_{2 l j}, r_{3 l j}, r_{4 l j}\right] ;\left[\mu_{l j}^{L}, \mu_{l j}^{U}\right] ;\left[v_{l j}^{L}, v_{l j}^{U}\right]\right)\right\}=J \\
& -C_{k, l} .
\end{aligned}
$$

Step 5 (calculation of IVITFN concordance matrix). The concordance index $C \widetilde{I}_{k, l}$ reflects the relative importance of $A_{k}$ with respect to $A_{l}$. It is equal to the sum of IVITFN weights corresponding to the criteria which are contained in the concordance set $C_{k, l}$. Thus the concordance index is given by

$$
\begin{aligned}
& C \widetilde{I}_{k, l} \\
& \quad=\left(\left[C I_{1 k l}, C I_{2 k l}, C I_{3 k l}, C I_{4 k l}\right] ;\left[\mu_{k l}^{L}, \mu_{k l}^{U}\right] ;\left[v_{k l}^{L}, v_{k l}^{U}\right]\right) \\
& \quad=\sum_{j \in C_{k, l}}\left(\left[w_{1 j}, w_{2 j}, w_{3 j}, w_{4 j}\right] ;\left[\mu_{j}^{L}, \mu_{j}^{U}\right] ;\left[v_{j}^{L}, v_{j}^{U}\right]\right) .
\end{aligned}
$$

The successive values of the concordance indices $C \widetilde{I}_{k, l}(k, l=$ $1,2,3, \ldots, m$ and $k \neq l$ ) form the concordance matrix $C_{m \times m}$. Hence, the asymmetrical concordance IVITF matrix is as follows:

$$
C_{m \times m}=\left|\begin{array}{ccccc}
- & C \widetilde{I}_{1,2} & C \widetilde{I}_{1,3} & \cdots & C \widetilde{I}_{1, m} \\
C \widetilde{I}_{2,1} & - & C \widetilde{I}_{2,3} & \cdots & C \widetilde{I}_{2, m} \\
\cdots & \cdots & \cdots & \cdots & \cdots \\
C \widetilde{I}_{m, 1} & C \widetilde{I}_{m, 2} & C \widetilde{I}_{m, 3} & \cdots & C \widetilde{I}_{m, m}
\end{array}\right| .
$$

Step 6 (calculation of IVITFN discordance matrix). The discordance index $D I_{k, l}$ reflects the degree to which $A_{k}$ is worse than $A_{l}$. It is calculated for each element of discordance IVITFN set $D_{k, l}$, using the members of weighted normalized matrix $R$ as follows:

$$
D I_{k, l}=\frac{\max _{j \in D_{k, l}}\left\{\left|V\left(\left[r_{1 k j}, r_{2 k j}, r_{3 k j}, r_{4 k j}\right] ;\left[\mu_{k j}^{L}, \mu_{k j}^{U}\right] ;\left[v_{k j}^{L}, v_{k j}^{U}\right]\right)-\left(\left[r_{1 l j}, r_{2 l j}, r_{3 l j}, r_{4 l j}\right] ;\left[\mu_{l j}^{L}, \mu_{l j}^{U}\right] ;\left[v_{l j}^{L}, v_{l j}^{U}\right]\right)\right|\right\}}{\max _{j \in J}\left\{\left|V\left(\left[r_{1 k j}, r_{2 k j}, r_{3 k j}, r_{4 k j}\right] ;\left[\mu_{k j}^{L}, \mu_{k j}^{U}\right] ;\left[v_{k j}^{L}, v_{k j}^{U}\right]\right)-\left(\left[r_{1 l j}, r_{2 l j}, r_{3 l j}, r_{4 l j}\right] ;\left[\mu_{l j}^{L}, \mu_{l j}^{U}\right] ;\left[v_{l j}^{L}, v_{l j}^{U}\right]\right)\right|\right\}} .
$$


These computations convert IVITFNs to crisp numbers. Hence we get the discordance matrix with the crisp values. The successive values of the discordance indices $D I_{k, l}(k, l=$ $1,2,3, \ldots, m$ and $k \neq l$ ) form the discordance matrix $D_{m \times m}$ which is given by

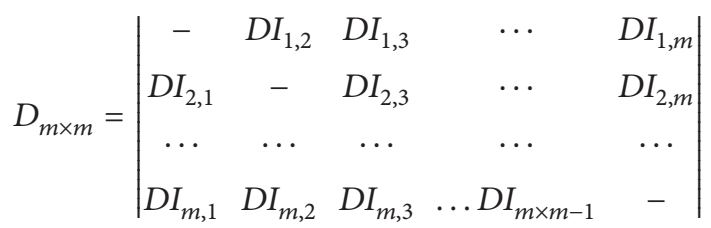

with $0 \leq D I_{k, l} \leq 1$ for $k, l=1,2,3, \ldots, m$.

Step 7 (determining the concordance IVITF dominance matrix). The concordance IVITF dominance matrix is calculated by comparing the values of concordance IVITF matrix $\left(C_{m \times m}\right)$ with threshold value $\left(C \widetilde{I}^{\prime}\right)$. It indicates alternative $A_{k}$ 's chance of dominating alternative $A_{l}$. The threshold is the average of concordance IVITF index; that is,

$$
\begin{aligned}
& C \widetilde{I}^{\prime}=\left(\left[C I_{1 k, l}^{\prime}, C I_{2 k, l}^{\prime}, C I_{3 k, l}^{\prime}, C I_{4 k, l}^{\prime}\right] ;\left[\mu_{k l}^{L}, \mu_{k l}^{U}\right] ;\left[v_{k l}^{L}, v_{k l}^{U}\right]\right) \\
& =\sum_{\substack{k=1 \\
k \neq l}}^{m} \sum_{\substack{l=1 \\
l \neq k}}^{m} \frac{\left(\left[C I_{1 k, l}, C I_{2 k, l}, C I_{3 k, l}, C I_{4 k, l}\right] ;\left[\mu_{k l}^{L}, \mu_{k l}^{U}\right] ;\left[v_{k l}^{L}, v_{k l}^{U}\right]\right)}{m(m-1)} .
\end{aligned}
$$

On the basis of this threshold value, $C \widetilde{I}^{\prime}$, a Boolean matrix $F$ is constructed as follows:

$$
f_{k, l}= \begin{cases}1 & \text { if } C \widetilde{I} \geq C \widetilde{I}^{\prime} \\ 0 & \text { if } C \widetilde{I}<C \widetilde{I}^{\prime}\end{cases}
$$

Element 1 in the Boolean matrix $F$ represents the dominance of one alternative with respect to the other.

Step 8 (determining the discordance IVITF dominance matrix). In a similar way, the discordance IVITF dominance matrix can be calculated with the help of discordance indices and the threshold value $D I^{\prime}$ which is given as follows:

$$
D I^{\prime}=\sum_{\substack{k=1 \\ k \neq l}}^{m} \sum_{\substack{l=1 \\ l \neq k}}^{m} \frac{N I_{k, l}}{m(m-1)} .
$$

The elements $g_{k, l}$ of the Boolean matrix $G$ are calculated as follows:

$$
\begin{array}{ll}
g_{k, l}=1 & \text { if } D I_{k, l} \leq D I^{\prime} \\
g_{k, l}=0 & \text { if } D I_{k, l}>D I^{\prime} .
\end{array}
$$

Element 1 in the Boolean matrix $G$ represents the dominance of one alternative with respect to the other.

Step 9 (estimating the aggregate dominance matrix). The aggregate dominance matrix $T$ is the intersection of concordance IVITF dominance matrix $F$ and discordance IVITF dominance matrix $G$. The elements $t_{k l}$ of $T$ are defined as

$$
t_{k, l}=f_{k, l} \cdot g_{k, l} \text {. }
$$

The aggregate dominance matrix indicates the partial preference ordering of the alternatives. If $t_{k, l}=1$, then $A_{k}$ is preferred to $A_{l}$ in terms of both concordance criteria and discordance criteria. In this case the alternative $A_{l}$ is eliminated. However, $A_{k}$ may be dominated by other alternatives. Hence, the condition which makes alternative $A_{k}$ more effective is defined as follows:

$$
\begin{aligned}
& t_{k, l}=1 \quad \text { for at least one } l \text { for } l=1,2, \ldots, m ; k \neq l, \\
& t_{k, l}=0 \quad \forall i \text { for } i=1,2, \ldots, m ; i \neq k ; i \neq l
\end{aligned}
$$

\section{Numerical Example}

In this section, the proposed IVITF-ELECTRE method is illustrated by taking two real world problems discussed in the literature.

Example 1. The proposed method is applied to find the best green supplier for one of the key elements in the manufacturing process of a food company presented by Wu and Liu [24]. After preevaluation, the company has selected three suppliers (alternatives) for further evaluation and evaluated them based on four criteria: product quality $\left(C_{1}\right)$, technology capability $\left(C_{2}\right)$, pollution control $\left(C_{3}\right)$, and environmental management $\left(C_{4}\right)$. Three decision makers, namely, $\mathrm{DM}_{1}, \mathrm{DM}_{2}$, and $\mathrm{DM}_{3}$, are chosen from three different departments, namely, production, purchasing, and quality inspection. Assessments of three suppliers by three decision makers based on each criterion are given, respectively, in Tables 1, 2, and 3 .

Weights of each criterion are given as

$$
\begin{aligned}
& W_{\left\{c_{1}, c_{2}, c_{3}, c_{4}\right\}} \\
& \quad=\{([0.3,0.4,0.5,0.6] ;[0.3,0.5],[0.1,0.2]), \\
& \quad([0.3,0.4,0.5,0.6] ;[0.4,0.5],[0.3,0.4]), \\
& \quad([0.2,0.4,0.5,0.6] ;[0.4,0.6],[0.2,0.4]), \\
& \quad([0.4,0.5,0.7,0.8] ;[0.3,0.4],[0.2,0.4])\} .
\end{aligned}
$$

The decision matrix $D$ for the given data using Step 1 is calculated and presented in Table 4 .

The normalized decision matrix and weighted normalized decision matrices are calculated using (36) and (37) and, respectively, given in Tables 5 and 6 .

Concordance and discordance sets are estimated using (38) and (39) and are as follows:

$$
\begin{aligned}
& C_{1,2}=\{1,2\}, \\
& C_{1,3}=\{1,2,3,4\}, \\
& C_{2,1}=\{3,4\}, \\
& C_{2,3}=\{1,2,3,4\}, \\
& C_{3,1}=\phi,
\end{aligned}
$$


TABLE 1: Assessment by $\mathrm{DM}_{1}$.

\begin{tabular}{lccc}
\hline Criteria & \multicolumn{3}{c}{ Suppliers } \\
& $A_{1}$ & $A_{2}$ & $A_{3}$ \\
\hline$C_{1}$ & $([0.2,0.3,0.4,0.5] ;[0.3,0.6],[0.1,0.3])$ & $([0.1,0.3,0.4,0.5] ;[0.5,0.6],[0.2,0.4])$ & $([0.3,0.5,0.6,0.7] ;[0.3,0.4],[0.2,0.3])$ \\
$C_{2}$ & $([0.4,0.6,0.7,0.8] ;[0.4,0.7],[0.1,0.2])$ & $([0.2,0.4,0.5,0.8] ;[0.4,0.5],[0.3,0.4])$ & $([0.1,0.3,0.4,0.5] ;[0.4,0.6],[0.1,0.2])$ \\
$C_{3}$ & $([0.3,0.5,0.6,0.8] ;[0.3,0.4],[0.2,0.3])$ & $([0.4,0.6,0.8,1.0] ;[0.4,0.6],[0.2,0.4])$ & $([0.2,0.3,0.4,0.5] ;[0.4,0.5],[0.3,0.4])$ \\
$C_{4}$ & $([0.1,0.3,0.4,0.6] ;[0.6,0.7],[0.2,0.3])$ & $([0.3,0.5,0.6,0.7] ;[0.3,0.5],[0.1,0.4])$ & $([0.1,0.2,0.3,0.5] ;[0.2,0.5],[0.1,0.4])$ \\
\hline
\end{tabular}

TABLE 2: Assessment by $\mathrm{DM}_{2}$.

\begin{tabular}{lccc}
\hline Criteria & \multicolumn{3}{c}{ Suppliers } \\
& $A_{1}$ & $A_{2}$ & $A_{3}$ \\
\hline$C_{1}$ & $([0.6,0.7,0.8,0.9] ;[0.6,0.7],[0.1,0.2])$ & $([0.5,0.6,0.7,0.8] ;[0.5,0.6],[0.3,0.4])$ & $([0.7,0.8,0.9,1.0] ;[0.5,0.8],[0.1,0.2])$ \\
$C_{2}$ & $([0.1,0.2,0.4,0.5] ;[0.3,0.5],[0.2,0.4])$ & $([0.4,0.5,0.6,0.8] ;[0.4,0.6],[0.2,0.3])$ & $([0.3,0.4,0.5,0.6] ;[0.5,0.6],[0.2,0.4])$ \\
$C_{3}$ & $([0.3,0.4,0.5,0.6] ;[0.5,0.6],[0.3,0.4])$ & $([0.1,0.2,0.3,0.5] ;[0.4,0.6],[0.2,0.4])$ & $([0.2,0.3,0.4,0.5] ;[0.7,0.8],[0.1,0.2])$ \\
$C_{4}$ & $([0.1,0.3,0.4,0.5] ;[0.5,0.7],[0.2,0.3])$ & $([0.3,0.5,0.6,0.8] ;[0.3,0.4],[0.1,0.2])$ & $([0.2,0.3,0.4,0.5] ;[0.4,0.7],[0.2,0.3])$ \\
\hline
\end{tabular}

$$
\begin{aligned}
& C_{3,2}=\phi, \\
& D_{1,2}=\{3,4\}, \\
& D_{1,3}=\phi, \\
& D_{2,1}=\{1,2\}, \\
& D_{2,3}=\phi, \\
& D_{3,1}=\{1,2,3,4\}, \\
& D_{3,2}=\{1,2,3,4\} .
\end{aligned}
$$

Based on the concordance sets obtained and using (40), the concordance index and concordance IVITF matrix are calculated and are given below.

For instance,

$$
\begin{aligned}
C \widetilde{I}_{1,2}= & \left(\left[w_{11}, w_{21}, w_{31}, w_{41}\right] ;\left[\mu_{1}^{L}, \mu_{1}^{R}\right] ;\left[v_{1}^{L}, v_{1}^{R}\right]\right) \\
& \oplus\left(\left[w_{12}, w_{22}, w_{32}, w_{42}\right] ;\left[\mu_{2}^{L}, \mu_{2}^{R}\right] ;\left[v_{2}^{L}, v_{2}^{R}\right]\right) \\
= & ([0.3,0.4,0.5,0.6] ;[0.3,0.5] ;[0.1,0.2]) \\
& \oplus([0.3,0.4,0.5,0.6] ;[0.4,0.5] ;[0.3,04]) \\
= & ([0.6,0.8,1.0,1.2] ;[0.3,0.5],[0.3,0.4]) .
\end{aligned}
$$

Similarly, we get

$$
\begin{aligned}
& C \widetilde{I}_{1,3}=([1.2,1.7,2.2,2.6] ;[0.3,0.4],[0.3,0.4]), \\
& C \widetilde{I}_{2,1}=([0.6,0.9,1.2,1.4] ;[0.3,0.4],[0.2,0.4]), \\
& C \widetilde{I}_{2,3}=([1.2,1.7,2.2,2.6] ;[0.3,0.4],[0.3,0.4]), \\
& C \widetilde{I}_{3,1}=\phi \\
& C \widetilde{I}_{3,2}=\phi
\end{aligned}
$$

and the concordance IVITF matrix is

$$
C_{3 \times 3}=\left|\begin{array}{ccc}
- & C \widetilde{I}_{1,2} & C \widetilde{I}_{1,3} \\
C \widetilde{I}_{2,1} & - & C \widetilde{I}_{2,3} \\
C \widetilde{I}_{3,1} & C \widetilde{I}_{3,2} & -
\end{array}\right| .
$$

Calculation of discordance IVITF matrix is as follows.

The discordance index and discordance IVITF are calculated using (42) and are given as follows:

$$
\begin{aligned}
& D I_{1,2}=1, \\
& D I_{1,3}=0 \\
& D I_{2,1}=0 \\
& D I_{2,3}=0 \\
& D I_{3,1}=1, \\
& D I_{3,2}=1,
\end{aligned}
$$

and the discordance IVITF matrix is

$$
D_{3 \times 3}=\left|\begin{array}{ccc}
- & 1 & 0 \\
0 & - & 0 \\
1 & 1 & -
\end{array}\right| .
$$

Next, concordance dominance matrix is computed using the threshold value.

The threshold value of concordance index using (44) is

$$
\begin{aligned}
& C \widetilde{I}^{\prime}=\left(\left[C \widetilde{I}_{1 k, l}^{\prime}, C \widetilde{I}_{2 k, l}^{\prime}, C \widetilde{I}_{3 k, l}^{\prime}, C \widetilde{I}_{4 k, l}^{\prime}\right] ;\left[\mu_{k l}^{L}, \mu_{k l}^{U}\right] ;\left[v_{k l}^{L}, v_{k l}^{U}\right]\right) \\
& =\sum_{k=1}^{m} \sum_{l=1}^{m} \frac{\left(\left[C \widetilde{I}_{1 k, l}, C \widetilde{I}_{2 k, l}, C \widetilde{I}_{3 k, l}, C \widetilde{I}_{4 k, l}\right] ;\left[\mu_{k l}^{L}, \mu_{k l}^{U}\right] ;\left[v_{k l}^{L}, v_{k l}^{U}\right]\right)}{3(3-1)} \\
& =\frac{([3.6,5.1,6.6,7.8] ;[0.3,0.4],[0.3,0.4])}{6} \\
& =([0.6,0.85,1.1,1.3] ;[0.3,0.4],[0.3,0.4]) .
\end{aligned}
$$


TABLE 3: Assessment by $\mathrm{DM}_{3}$.

\begin{tabular}{lccc}
\hline Criteria & \multicolumn{3}{c}{ Suppliers } \\
& $A_{1}$ & $A_{2}$ & $A_{3}$ \\
\hline$C_{1}$ & $([0.4,0.5,0.6,0.7] ;[0.4,0.5],[0.3,0.4])$ & $([0.5,0.6,0.7,0.9] ;[0.3,0.6],[0.1,0.2])$ & $([0.3,0.4,0.5,0.6] ;[0.5,0.6],[0.1,0.4])$ \\
$C_{2}$ & $([0.5,0.6,0.7,0.9] ;[0.2,0.4],[0.1,0.2])$ & $([0.4,0.5,0.7,0.8] ;[0.4,0.5],[0.3,0.4])$ & $([0.2,0.3,0.4,0.5] ;[0.4,0.5],[0.2,0.5])$ \\
$C_{3}$ & $([0.4,0.5,0.6,0.7] ;[0.7,0.8],[0.1,0.2])$ & $([0.2,0.3,0.4,0.5] ;[0.6,0.8],[0.1,0.2])$ & $([0.2,0.4,0.5,0.6] ;[0.5,0.6],[0.2,0.4])$ \\
$C_{4}$ & $([0.5,0.6,0.7,0.8] ;[0.5,0.6],[0.2,0.4])$ & $([0.6,0.7,0.8,0.9] ;[0.3,0.4],[0.1,0.2])$ & $([0.7,0.8,0.9,1.0] ;[0.4,0.5],[0.3,0.5])$ \\
\hline
\end{tabular}

TABLE 4: Decision matrix D.

\begin{tabular}{lccc}
\hline Criteria & $A_{1}$ & Alternatives & $A_{3}$ \\
\hline$C_{1}$ & $([0.4,0.5,0.6,0.7] ;[0.4,0.5],[0.3,0.4])$ & $([0.36,0.5,0.6,0.73] ;[0.3,0.6],[0.3,0.4])$ & $([0.43,0.56,0.66,0.76] ;[0.3,0.4],[0.5,0.6])$ \\
$C_{2}$ & $([0.33,0.46,0.6,0.73] ;[0.2,0.4],[0.2,0.4])$ & $([0.33,0.46,0.6,0.8] ;[0.4,0.5],[0.3,0.4])$ & $([0.2,0.33,0.43,0.53] ;[0.4,0.5],[0.2,0.5])$ \\
$C_{3}$ & $([0.33,0.46,0.56,0.7] ;[0.3,0.4],[0.3,0.4])$ & $([0.23,0.36,0.5,0.66] ;[0.4,0.6],[0.2,0.4])$ & $([0.2,0.33,0.43,0.53] ;[0.4,0.5],[0.3,0.4])$ \\
$C_{4}$ & $([0.23,0.36,0.5,0.63] ;[0.5,0.6],[0.2,0.4])$ & $([0.4,0.56,0.66,0.8] ;[0.3,0.4],[0.1,0.4])$ & $([0.33,0.43,0.53,0.66] ;[0.2,0.5],[0.3,0.5])$ \\
\hline
\end{tabular}

Hence the concordance dominance matrix is as follows:

$$
F=\left|\begin{array}{ccc}
- & 0 & 1 \\
1 & - & 1 \\
0 & 0 & -
\end{array}\right|
$$

On the other hand, discordance dominance matrix is calculated using threshold value.

The threshold value of discordance index is

$$
D I^{\prime}=\sum_{k=1}^{3} \sum_{l=1}^{3} \frac{D I_{k, l}}{3(3-1)} .
$$

Hence the discordance dominance matrix is as follows:

$$
G=\left|\begin{array}{ccc}
- & 0 & 1 \\
1 & - & 1 \\
0 & 0 & -
\end{array}\right|
$$

Finally, the aggregate dominance matrix $T=F \cdot G$ is

$$
T=\left|\begin{array}{ccc}
- & 1 & 1 \\
1 & - & 1 \\
0 & 0 & -
\end{array}\right| \cdot\left|\begin{array}{ccc}
- & 0 & 1 \\
1 & - & 1 \\
0 & 0 & -
\end{array}\right|=\left|\begin{array}{ccc}
- & 0 & 1 \\
1 & - & 1 \\
0 & 0 & -
\end{array}\right| .
$$

Hence, by (49) and matrix $T$, the alternatives can be ordered as

$$
A_{2}>A_{1}>A_{3} \text {. }
$$

Example 2. An MCDM problem concerned with a customer who intends to buy an air conditioner is solved using proposed method taken from [34]. Three types of air conditioners (alternatives $\left.A_{i}(i=1,2,3)\right)$ are to be evaluated on four criteria (attributes): (1) quality $\left(C_{1}\right),(2)$ design $\left(C_{2}\right),(3)$ price $\left(C_{3}\right)$, and (4) level of after-sale service $\left(C_{4}\right)$. The crisp weighting vector of the criteria given in [34] is converted to suitable IVITFN in order to apply the proposed method. The assessments of three alternatives by a decision maker based on each criterion are given in Table 7 and the weights of each criterion are taken as

$$
\begin{aligned}
& W_{\left\{c_{1}, c_{2}, c_{3}, c_{4}\right\}} \\
& \quad=\{([0.1,0.2,0.3,0.4] ;[0.3,0.4],[0.2,0.3]), \\
& \quad([0.05,0.1,0.15,0.2] ;[0.3,0.5],[0.2,0.4]), \\
& \quad([0.1,0.3,0.4,0.5] ;[0.4,0.6],[0.3,0.4]), \\
& \quad([0.3,0.4,0.5,0.6] ;[0.4,0.5],[0.3,0.4])\} .
\end{aligned}
$$

The normalized decision matrix and weighted normalized decision matrices are calculated using (36) and (37) and, respectively, given in Tables 8 and 9 .

Concordance and discordance sets are estimated using (38) and (39) and are as follows:

$$
\begin{aligned}
& C_{1,2}=\{1,2,3,4\}, \\
& C_{1,3}=\{1,2,3,4\}, \\
& C_{2,1}=\phi, \\
& C_{2,3}=\{2\}, \\
& C_{3,1}=\phi, \\
& C_{3,2}=\{1,3,4\}, \\
& D_{1,2}=\phi, \\
& D_{1,3}=\phi, \\
& D_{2,1}=\{1,2,3,4\}, \\
& D_{2,3}=\{1,3,4\}, \\
& D_{3,1}=\{1,2,3,4\}, \\
& D_{3,2}=\{2\} .
\end{aligned}
$$




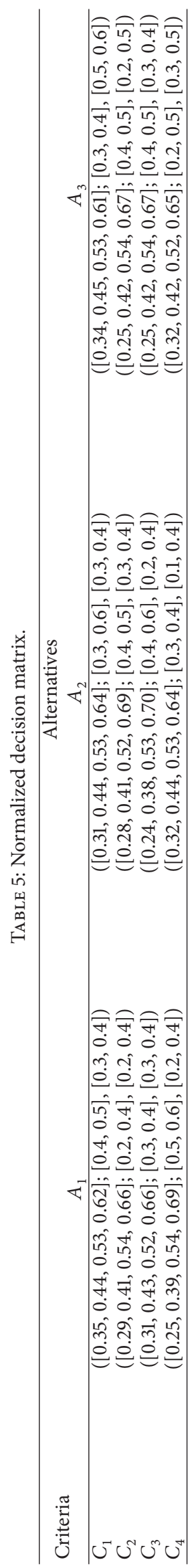




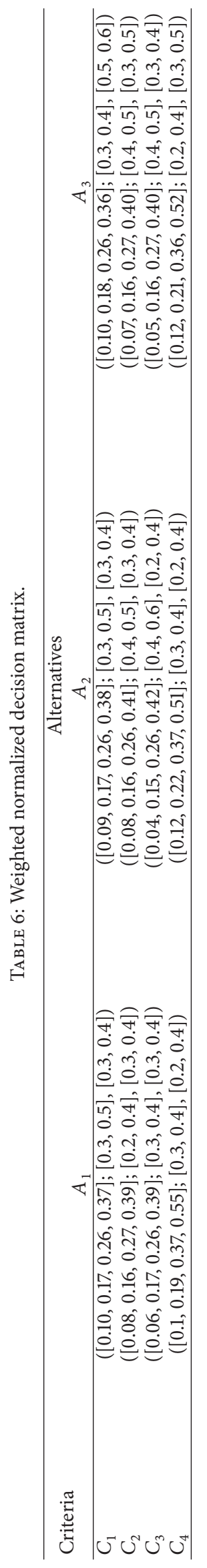


TABle 7: Decision matrix $D$.

\begin{tabular}{lccc}
\hline Criteria & $A_{1}$ & Alternatives & $A_{3}$ \\
\hline$C_{1}$ & $([0.1,0.2,0.3,0.4] ;[0.5,0.6],[0.2,0.3])$ & $([0.4,0.5,0.6,0.7] ;[0.3,0.5],[0.2,0.4])$ & $([0.2,0.4,0.5,0.8] ;[0.5,0.7],[0.1,0.2])$ \\
$C_{2}$ & $([0.2,0.3,0.4,0.5] ;[0.4,0.7],[0.2,0.3])$ & $([0.1,0.3,0.5,0.6] ;[0.2,0.4],[0.4,0.5])$ & $([0.2,0.3,0.4,0.5] ;[0.1,0.4],[0.5,0.6])$ \\
$C_{3}$ & $([0.3,0.4,0.5,0.6] ;[0.3,0.6],[0.3,0.4])$ & $([0.2,0.4,0.6,0.7] ;[0.4,0.7],[0.2,0.3])$ & $([0.1,0.2,0.4,0.5] ;[0.6,0.8],[0.1,0.2])$ \\
$C_{4}$ & $([0.1,0.3,0.5,0.6] ;[0.4,0.5],[0.2,0.4])$ & $([0.3,0.5,0.6,0.8] ;[0.0,0.3],[0.5,0.7])$ & $([0.1,0.2,0.4,0.6] ;[0.2,0.4],[0.3,0.6])$ \\
\hline
\end{tabular}

Accordingly, concordance and discordance matrices are calculated and are as follows.

The concordance IVITF matrix is

$$
C_{3 \times 3}=\left|\begin{array}{ccc}
- & C \widetilde{I}_{1,2} & C \widetilde{I}_{1,3} \\
C \widetilde{I}_{2,1} & - & C \widetilde{I}_{2,3} \\
C \widetilde{I}_{3,1} & C \widetilde{I}_{3,2} & -
\end{array}\right|,
$$

and the discordance IVITF matrix is

$$
D_{3 \times 3}=\left|\begin{array}{ccc}
- & \phi & \phi \\
1 & - & 1 \\
1 & 0.0292 & -
\end{array}\right| .
$$

Furthermore, the concordance dominance matrix and discordance dominance matrices are computed using the threshold value.

The threshold value of concordance index using (44) is

$$
\begin{aligned}
& C \widetilde{I}^{\prime}=\left(\left[C \tilde{I}_{1 k, l}^{\prime}, C \widetilde{I}_{2 k, l}^{\prime}, C \widetilde{C}_{3 k, l}^{\prime}, C \widetilde{I}_{4 k, l}^{\prime}\right] ;\left[\mu_{k l}^{L}, \mu_{k l}^{U}\right] ;\left[v_{k l}^{L}, v_{k l}^{U}\right]\right) \\
& =\sum_{k=1}^{m} \sum_{l=1}^{m} \frac{\left(\left[C \widetilde{I}_{1 k, l}, C \widetilde{I}_{2 k, l}, C \widetilde{I}_{3 k, l}, C \widetilde{I}_{4 k, l}\right] ;\left[\mu_{k l}^{L}, \mu_{k l}^{U}\right] ;\left[v_{k l}^{L}, v_{k l}^{U}\right]\right)}{3(3-1)} \\
& =\frac{([1.65,3,4.05,5.1] ;[0.3,0.4],[0.3,0.4])}{6} \\
& =([0.275,0.5,0.675,0.85] ;[0.3,0.4],[0.3,0.4]),
\end{aligned}
$$

and the threshold value of discordance index is

$$
D I^{\prime}=\sum_{k=1}^{3} \sum_{l=1}^{3} \frac{D I_{k, l}}{3(3-1)}
$$

Hence, the concordance dominance and discordance dominance matrices are, respectively, obtained as

$$
\begin{aligned}
F & =\left|\begin{array}{ccc}
- & 1 & 1 \\
0 & - & 0 \\
0 & 1 & -
\end{array}\right|, \\
G & =\left|\begin{array}{lll}
- & 1 & 1 \\
0 & - & 0 \\
0 & 1 & -
\end{array}\right| .
\end{aligned}
$$

Finally, the aggregate dominance matrix $T=F \cdot G$ is

$$
T=\left|\begin{array}{ccc}
- & 1 & 1 \\
0 & - & 0 \\
0 & 1 & -
\end{array}\right| .
$$

Therefore, the alternatives can be ordered as

$$
A_{1}>A_{3}>A_{2} \text {. }
$$

This means that $A_{1}$ is the best alternative which agrees with human intuition as $A_{1}$ 's performance is better when compared to other alternatives in the criteria $C_{3}$ and $C_{4}$ which are given more weight in decision making process.

\section{Conclusion}

In a multicriteria group decision making method, the experts often quantify their opinion in the form of an interval on a consecutive set. Hence, it is more suitable to represent and study the decision making problems using IVITFNs. Based on this fact, we proposed ELECTRE method to find the best alternative when the criterion and weights of criterion are IVITFNs. The advantage of the proposed method over existing aggregated methods is that the proposed method retains the fuzziness of criterion weights during computation, while the aggregated methods use the weights and convert them into crisp numbers in the initial step itself. Furthermore, the proposed ranking method of IVITFNs using value and ambiguity index of membership and nonmembership allows studying the IVITFNs in a statistical manner and also takes expert's risk attitude into consideration while comparing the fuzzy numbers. It is also observed that the proposed ranking can rank the IVITFNs more accurately when compared to existing methods of ranking IVITFNs. Finally, the proposed method was illustrated by applying it to real world problems: finding the best green supplier for one of the key elements in the manufacturing process of a food company and selecting the best air conditioner from a customer perspective. The comparison reveals that the proposed method can rank the alternatives more strictly compared to the method of $\mathrm{Wu}$ and Liu. In the future, we will focus on applying the proposed method to other ELECTRE methods. 


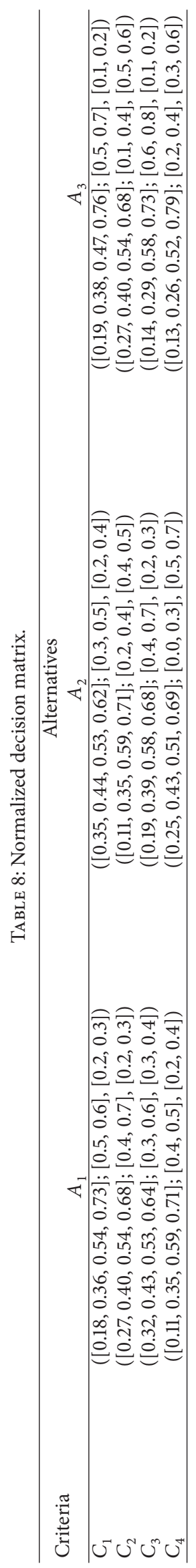




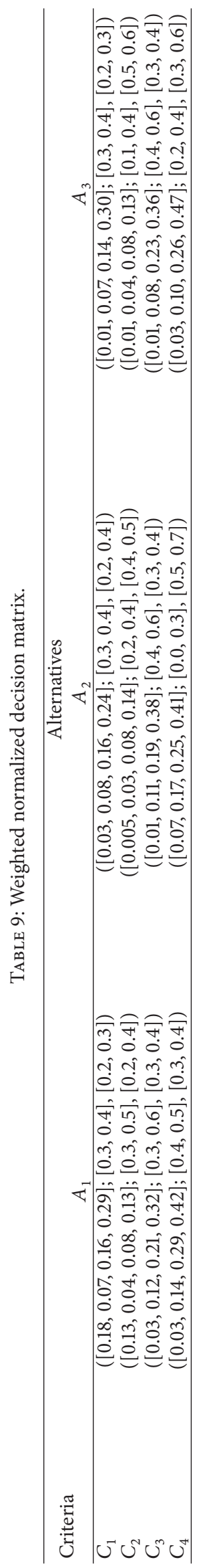




\section{Competing Interests}

The authors declare that there are no competing interests regarding the publication of this paper.

\section{References}

[1] L. A. Zadeh, "Fuzzy sets," Information and Computation, vol. 8, pp. 338-353, 1965.

[2] K. Atanassov, "Intuitonistic fuzzy sets," Fuzzy Sets and Systems, vol. 20, pp. 87-96, 1986 .

[3] B. Vahdani and H. Hadipour, "Extension of the ELECTRE method based on interval-valued fuzzy sets," Soft Computing, vol. 15, no. 3, pp. 569-579, 2011.

[4] K. Atanassov and G. Gargov, "Interval valued intuitionistic fuzzy sets," Fuzzy Sets and Systems, vol. 31, no. 3, pp. 343-349, 1989.

[5] J. Wu and Q.-w. Cao, "Same families of geometric aggregation operators with intuitionistic trapezoidal fuzzy numbers," Applied Mathematical Modelling, vol. 37, no. 1-2, pp. 318-327, 2013.

[6] M.-H. Shu, C.-H. Cheng, and J.-R. Chang, "Using intuitionistic fuzzy sets for fault-tree analysis on printed circuit board assembly," Microelectronics Reliability, vol. 46, no. 12, pp. 21392148, 2006.

[7] J. Q. Wang, "Overview on fuzzy multi-criteria decision making approach," Control and Decision, vol. 23, pp. 601-606, 2008.

[8] S. P. Wan, "Multi-attribute decision making method based on interval-valued intuitionistic trapezoidal fuzzy number," Control and Decision, vol. 26, no. 6, pp. 857-860, 2011.

[9] R. E. Bellman and L. A. Zadeh, "Decision making in fuzzy environment," Management Science, vol. 17, no. 4, pp. 141-164, 1970.

[10] S.-M. Chen and L.-W. Lee, "Fuzzy multiple criteria hierarchical group decision-making based on interval type-2 fuzzy sets," IEEE Transactions on Systems, Man, and Cybernetics Part A:Systems and Humans, vol. 40, no. 5, pp. 1120-1128, 2010.

[11] Z.-W. Gong, L.-S. Li, J. Forrest, and Y. Zhao, "The optimal priority models of the intuitionistic fuzzy preference relation and their application in selecting industries with higher meteorological sensitivity," Expert Systems with Applications, vol. 38, no. 4, pp. 4394-4402, 2011.

[12] E. Herrera-Viedma, F. Chiclana, F. Herrera, and S. Alonso, "Group decision-making model with incomplete fuzzy preference relations based on additive consistency," IEEE Transactions on Systems, Man, and Cybernetics Part B: Cybernetics, vol. 37, no. 1, pp. 176-189, 2007.

[13] H.-W. Liu and G.-J. Wang, "Multi-criteria decision-making methods based on intuitionistic fuzzy sets," European Journal of Operational Research, vol. 179, no. 1, pp. 220-233, 2007.

[14] P. Liu and F. Jin, "A multi-attribute group decision-making method based on weighted geometric aggregation operators of interval-valued trapezoidal fuzzy numbers," Applied Mathematical Modelling, vol. 36, no. 6, pp. 2498-2509, 2012.

[15] J.-Q. Wang and Z. Zhang, "Multi-criteria decision-making method with incomplete certain information based on intuitionistic fuzzy number," Control and Decision, vol. 24, no. 2, pp. 226-230, 2009.

[16] J.-Q. Wang, K.-J. Li, and H.-Y. Zhang, "Interval-valued intuitionistic fuzzy multi-criteria decision-making approach based on prospect score function," Knowledge-Based Systems, vol. 27, pp. 119-125, 2012.

[17] G. W. Wei, X. F. Zhao, and H. J. Wang, "An approach to multiple attribute group decision making with interval intuitionistic trapezoidal fuzzy information," Technological and Economic Development of Economy, vol. 18, no. 2, pp. 317-330, 2012.

[18] Z. S. Xu, "Intuitionistic preference relations and their application in group decision making," Information Sciences, vol. 177, no. 11, pp. 2363-2379, 2007.

[19] Z. S. Xu, "Approaches to multiple attribute group decision making based on intuitionistic fuzzy power aggregation operators," Knowledge-Based Systems, vol. 24, no. 6, pp. 749-760, 2011.

[20] Z. S. Xu and J. Chen, "An approach to group decision making based on interval-valued intuitionistic judgment matrices," System Engineer-Theory and Practice, vol. 27, pp. 126-133, 2007.

[21] N. Yayala and M. Karacasu, "A decision support model to incorporate public and expert opinions for assessing the privatization of public bus transit system: application of ELECTRE for the bus system in Eskisehir, Turkey," Scientific Research and Essays, vol. 6, no. 21, pp. 4657-4664, 2011.

[22] P. P. Angelov, "Optimization in an intuitionistic fuzzy environment," Fuzzy Sets and Systems, vol. 86, no. 3, pp. 299-306, 1997.

[23] D.-F. Li and S.-P. Wan, "Fuzzy linear programming approach to multiattribute decision making with multiple types of attribute values and incomplete weight information," Applied Soft Computing Journal, vol. 13, no. 11, pp. 4333-4348, 2013.

[24] J. Wu and Y. Liu, "An approach for multiple attribute group decision making problems with interval-valued intuitionistic trapezoidal fuzzy numbers," Computers \& Industrial Engineering, vol. 66, no. 2, pp. 311-324, 2013.

[25] N. Zhang and G. Wei, "Extension of VIKOR method for decision making problem based on hesitant fuzzy set," Applied Mathematical Modelling, vol. 37, no. 7, pp. 4938-4947, 2013.

[26] R. Benayoun, B. Roy, and N. Sussman, Manual de Reference du Programme Electre, Note de Synthese et Formation, No. 25, Direction Scientific SEMA, Paris, France, 1966.

[27] J. Mustajoki, R. P. Hämäläinen, and A. Salo, "Decision support by interval SMART/SWING_-incorporating imprecision in the SMART and SWING methods," Decision Sciences, vol. 36, no. 2, pp. 317-339, 2005.

[28] J. Figueria, V. Mousseau, and B. Roy, "ELECTRE methods," in Multiple Criteria Decision Analysis: State of the Art Surveys, J. Figuera, S. Greco, and M. Ehrgott, Eds., pp. 133-153, Springer, Boston, Mass, USA, 2005.

[29] M. Sevkli, "An application of the fuzzy ELECTRE method for supplier selection," International Journal of Production Research, vol. 48, no. 12, pp. 3393-3405, 2010.

[30] B. Vahdani, A. H. K. Jabbari, V. Roshanaei, and M. Zandieh, "Extension of the ELECTRE method for decision-making problems with interval weights and data," International Journal of Advanced Manufacturing Technology, vol. 50, no. 5-8, pp. 793-800, 2010.

[31] G. Wei, X. Zhao, and H. Wang, "An approach to multiple attribute group decision making with interval intuitionistic trapezoidal fuzzy information," Technological and Economic Development of Economy, vol. 18, no. 2, pp. 317-330, 2012.

[32] P. K. De and D. Das, "A study on ranking of trapezoidal intuitionistic fuzzy numbers," International Journal of Computer Information System and Industrial Management Applications, vol. 6, pp. 437-444, 2014. 
[33] M. Delgado, M. A. Vila, and W. Voxman, "On a canonical representation of fuzzy numbers," Fuzzy Sets and Systems, vol. 93, no. 1, pp. 125-135, 1998.

[34] M. Tian and J. Liu, "Some aggregation operators with intervalvalued intuitionistic trapezoidal fuzzy numbers and their application in multiple attribute decision making," Advanced Modeling and Optimization, vol. 15, no. 2, 2013. 

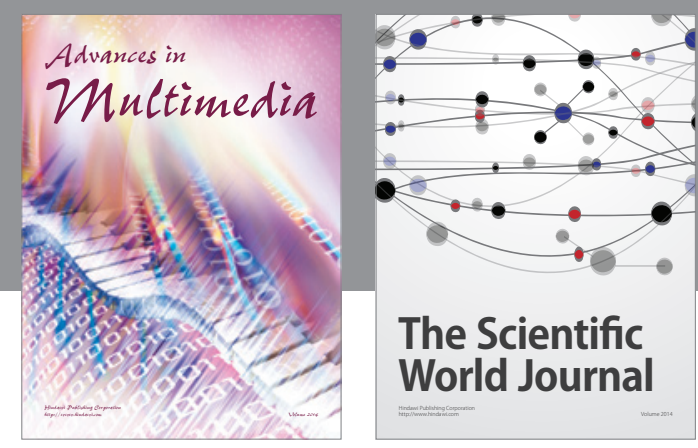

The Scientific World Journal
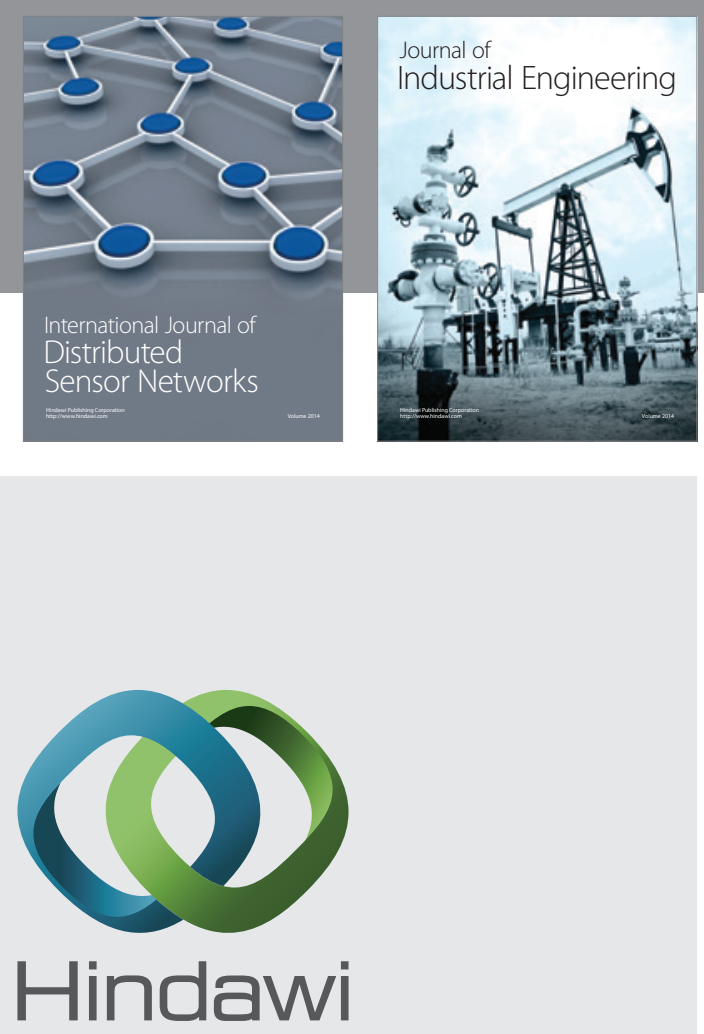

Submit your manuscripts at

http://www.hindawi.com

\section{Computer Networks} and Communications
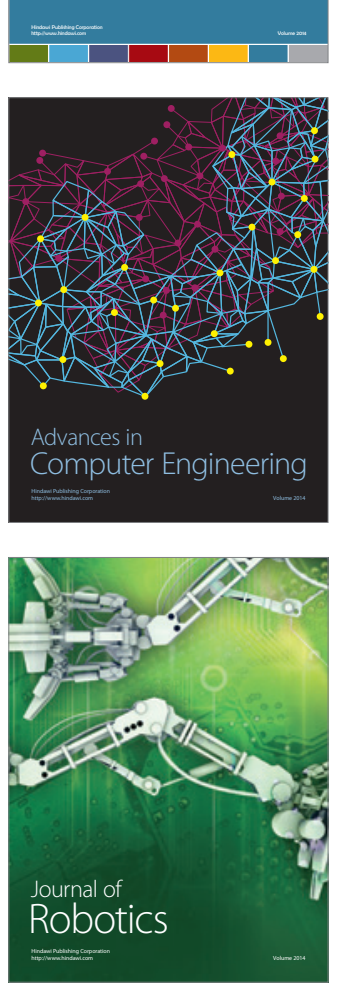
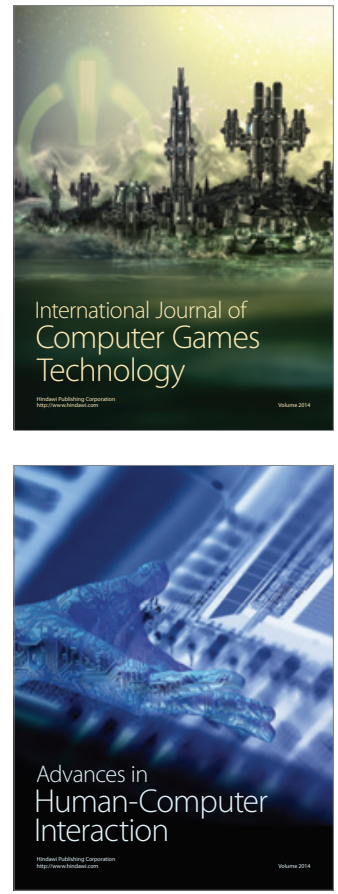
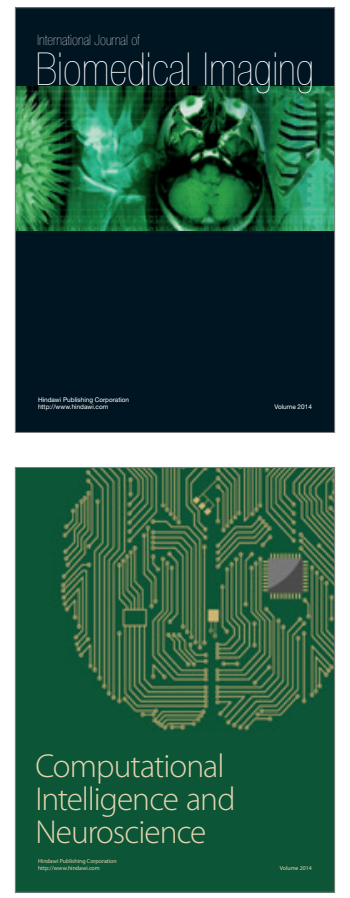
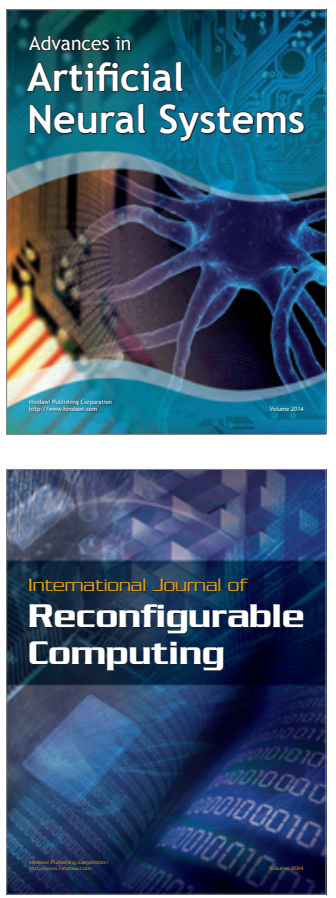
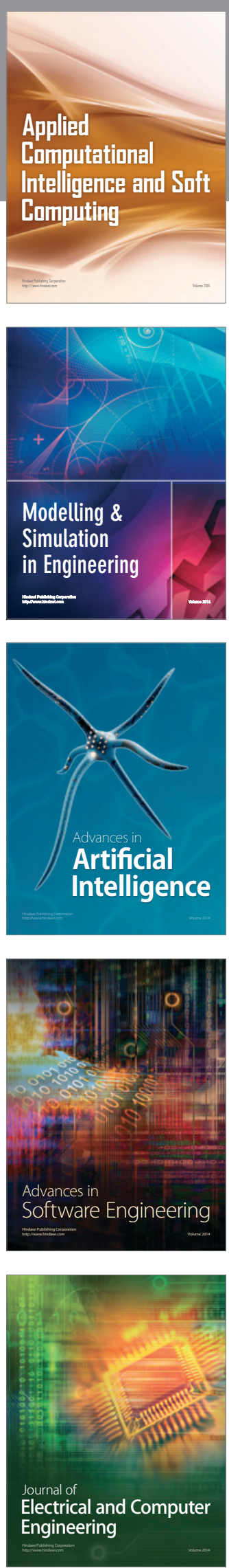